\title{
Differential effect of pre and post cognitive skills training program: a study on healthy young children
}

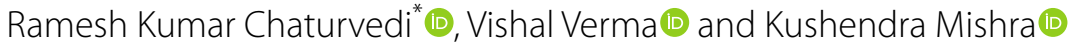

\author{
*Correspondence: \\ rameshkrc@bbau.ac.in \\ Department of Rural \\ Management, School \\ of Management Studies, \\ Babasaheb Bhimrao \\ Ambedkar University \\ (A Central University), \\ VidyaVihar, Rae Bareilly Road, \\ Near Rama Bai Ambedkar \\ Maidan, Shaheed Path, \\ Lucknow 226025, India
}

\begin{abstract}
The objective of this research paper is to check the difference between pre and post-session of the Brighter Minds based Cognitive Skill Training. The exploratory and descriptive research design is used in this study. In this investigation, the nine measurement variables are selected for the study such as memory, confidence, concentration, intuition ability, and blindfold reading. All the measurement variables were tested under pre and post cognitive skill training. Apart from these behavioural variables, two variables, gender, and age were also measured. The paired $t$ test is used for the comparison between the pre and post-session of cognitive skill training. The pie and bar chart is used for the pictorial presentation of the results. The data coding, value label, data analysis are performed through statistical software. The findings of this study concluded that there was a significant improvement in the student's memory, confidence, concentration, intuition, and skill of reading and colour identification with a blindfold.
\end{abstract}

Keywords: Cognitive skills, Ancient, Wisdom, Brain training

\section{Introduction}

UNO's Sustainable Development Goal (SDG) 'goal 4' aims to ensure inclusive and equitable quality education and promote lifelong learning for all by 2030 (PrietoJiménez et al., 2021; United Nations, 2021). These goals are to be met in an environment where the world is facing technology driven information overload and going through a complex transition. Under such an environment there is a need to develop and adopt intuitive and cognitive learning pedagogies. India the spiritual motherland (Ghosh, 2007; Sharma, 2013b) since ancient times followed unique pedagogy based on the technique of transmission power (known as Pranahuti) involving Sruti (To Listen) and the Smriti (To memorize) for intuitive and cognitive learning (Ghosh, 2007; Monk, 1968; Sharma, 2013a, 2013b; Thaker, 2007). Through such ancient cognitive skill accentuating methods when coupled with modern techniques such as 'neuroplasticity', the brain's ability to reorganize itself by forming new neural connections throughout life (Petzinger et al., 2013), students could learn anything very fast and these techniques of learning are poised to disrupt the education system in the future

(c) The Author(s) 2022. Open Access This article is licensed under a Creative Commons Attribution 4.0 International License, which permits use, sharing, adaptation, distribution and reproduction in any medium or format, as long as you give appropriate credit to the original author(s) and the source, provide a link to the Creative Commons licence, and indicate if changes were made. The images or other third party material in this article are included in the article's Creative Commons licence, unless indicated otherwise in a credit line to the material. If material is not included in the article's Creative Commons licence and your intended use is not permitted by statutory regulation or exceeds the permitted use, you will need to obtain permission directly from the copyright holder. To view a copy of this licence, visit http:// creativecommons.org/licenses/by/4.0/. 
in a very positive way (Kleim \& Jones, 2008; Sudhof \& Malenka, 2008). Such modern cognitive training techniques embedded in ancient wisdom for enhancing cognitive skills is being practiced in India by certain companies and among them, one that has gained popularity is the 'Brighter Minds' (BM) program. BM is a brain training program with a vision to unlock the potential in children through enhancing their sensory perceptions and cognitive functions. The program consists of $30 \mathrm{~h}$ of training for eight weeks with two consecutive sessions in the first week and seven follow-up sessions over the weekends, each session lasting about $3.0 \mathrm{~h}$ except for two sessions that are of $4.5 \mathrm{~h}$ each. The BM training program is offered to those children who are not diagnosed with any psychological disorders and/or known for major cognitive deficits. In a pre and post experimental design study, participants were able to properly utilize the left and right brains simultaneously and significant improvement in their intuitive and cognitive skills was found.

\section{Cognitive skills training (CST) based on brighter minds methods}

Brighter Minds is an educational initiative to help children develop their sense of observation and cognitive abilities, through enhancing and enriching the capabilities of their minds. This cognitive skill training program based on the Brighter Minds method includes prayer and circle time, key to success, key to happiness, brain exercise such as one of them is simultaneously making a circle with one index finger and making a square with other index finger, dance and motivational video, fun video, super memory games/illusions, eyeball exercise like rotating the eyeball in a shape of the coil without moving the head, rotating the eyeball in triangle shape, hexagon shape, up and down, etc. This training method also includes music therapy with Alpha wave frequency- $(8-12 \mathrm{~Hz})$ for the relaxations, meditative, calm state, Beta(12-25 Hz) during active concentration, and Gama-(more than $25 \mathrm{~Hz}$ ), during high activity. These music frequencies when synchronize with the brain wave frequency, create the most favourable environment for boosting working memory, performing psychological and psychophysiological tasks, learning, enhancing concentration, and creativity (Bigliassi et al., 2020; Mikhailova et al., 2021). Under blindfold activities, touch, smell, and sound are all exercised initially. In later sessions the blindfold activities involves colour identification, number identification, segregating/ sorting multiple objects, colouring, leg sensing, reading and writing, distance object identification, distance reading, jigsaw puzzles, and obstacle walking. Eight weeks of training sessions based on these and some other techniques are used to enhance the brain capabilities of participants. Some of these tools have roots in Indian ancient wisdom. These modern teaching techniques are more or less similar to the ancient teaching where a Sadguru creates an environment of Alpha state $(8-12 \mathrm{~Hz})$ of mind through the use of yogic transmission (Pranahuti) which is the most suitable environment for learning, memory, and creativity ( www.brighterminds.org).

The Fig. 1 depicts the application of CST where a trained student is reading the medical book with a blindfold in front of doctors and medical practitioners in King George's Medical University (KGMU), Lucknow, Uttar Pradesh, India.

In order to structure the study, the following objective is taken: 


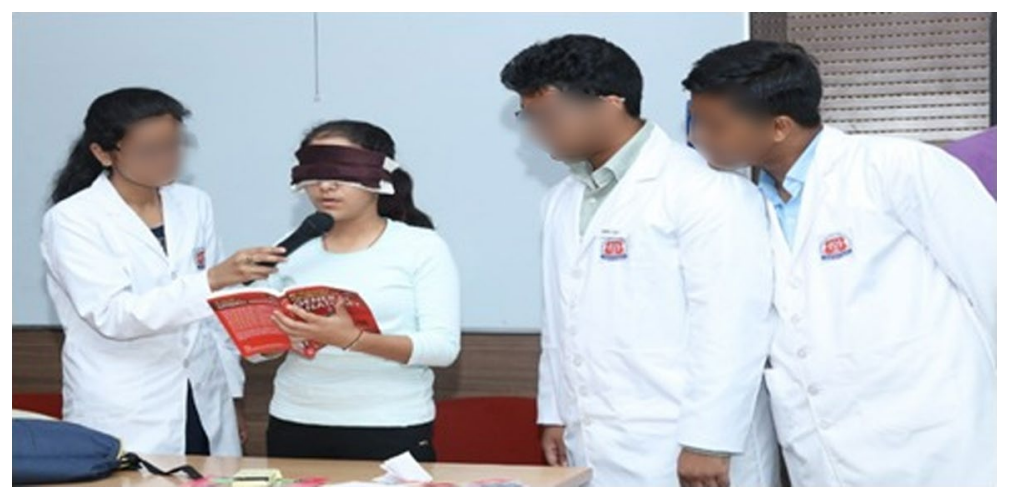

Fig. 1 Live demonstration of brighter minds based cognitive skill training (CST)

- To study the differential effect of the Brighter Minds based cognitive skill training on memory, confidence, concentration, intuition, and blindfold reading ability of students aged between 7 to 17 years.

\section{Literature review}

In this article, we posit that through Brighter Minds based cognitive training children can be trained with skills through which they could transcendent their ordinary capabilities and perform activities that are super physical. Our position is based on the confluence of ancient as well as modern methods of learning. The conceptualisation of transcending from known realities to realities that are non-physical or super-physical is not new but dates back to primordial traditions or cosmologies of every known human society, be it Judeo-Christian, Muslim, Buddhism, or Hinduism (Abrams \& Primack, 2001; Wilber, 1993; Roeser, 2005). Under such primordial traditions, human beings are considered as part of an unbroken continuum or spectrum of levels of being generally referred as 'Great nest of being'; which express matter, mental and spiritual level as a unified whole (Smith, 1992). Philosophy of 'Great nest of being' could be closely approximated to Panch-kosha (Five Sheath) and three bodies system model of 'cosmic hierarchy' mentioned in Taittiriya Upanishad. According to this model every human being has three bodies, one is the physical body, the second is a crystal/Subtle/Astral body and the third is the causal body. The physical body is a subject matter of fitness, the crystal body is a subject matter of mind, mediation and the causal body is a subject matter of soul, sub and super consciousness (Raina, 2016). Panch-kosha is the layers surrounding the mind and crystal bodies of the learner that needs to be overcome to reach the stage of all-encompassing experience of the fullness of self and the world (Hiriyanna, 2005; Swami Gambhirananda, 1958 cited in Raina, 2016). Upanishadic wisdom explicitly describes the teaching-learning process through the combined operation of Atma, Maya, Antahkarana, and Pancha pranas to overcome these layers (Ramabrahmam, 2005). The human mind alternates between two conscious states dvaita [(Two-aham-idam) (Jagrat (wakeful conscious state) and Swapna (dream conscious state)] and advaita [(only one-aham-aham) (the JagratSushupti- conscious state)]. Unlike dvaita conscious state where the learner 
recognises the difference between Knower and Known, in advaita conscious state knower and known blend into one and only knowing exists in form of experienced learning, meaningful experience, and understanding-the cognitive energy form. Mind by alternating between dvaita and advaita conscious states enables humans to learn, know, reason, be intellectual, experience, and be peaceful, etc. (Ramabrahmam, 1997, 2004 as mentioned in Ramabrahmam (2005)). Further Ramabrahmam (2005) explained in concluding remarks that "modern-day technology such as artificial intelligence and neural networking can be attributed to the essence or gist of human cognitive process and language communication process as envisaged by the Upanishads and the advaita philosophy together with Sabdmabrahma Theory (as propagated by Sri Ramana Maharshi and Sri Aurobindo independently)".Therefore we see Vedas and Upanishads have enough information that could be instrumental in our understanding of cognitive training and learning outcomes such as super physical abilities.

Knowledge of ancient methods of teaching and learning could only be useful if we blend it with the contemporary world of teaching and learning. In the modern environment of teaching and learning role of cognitive skill training (CST) is well acknowledged in enhancing learning outcomes (Bongarala et al., 2019; Gallen \& D’Esposito, 2019; Solis et al., 2019). Moreover, due to recent development in cognitive neuroscience, a field of study that focuses on understanding the higher level of the cognition process, now our understanding of the complex process of cognitive development through CST has also improved (Goswami, 2010; Shaywit, 2003). Due to these encouraging developments happening in the joint field of Neuroscience and Education authors like Katzir and Pare-Blagoev (2006) proposed to integrate research focusing on neurosciences and education psychology leading to a new discipline termed "Educational Neurosciences" or "Neuroeducation".

One aspect of researches that is happening in the field of "Neuroeducation" is exploring the possibilities of developing cognitive traits through CST. CST involves noninvasive interventions under which individuals are trained on one or more cognitive functions over a period of time with an aim to improve cognitive skills and related behaviours (Baniqued \& Gallen, 2019; Gallen \& D'Esposito, 2019). CST could be conducted through various methods and techniques such as short-term, long-term, group = based, technology-assisted, or computer-based. These methods have an impact on various cognitive traits of recipients such as memory retrieval, concentration, confidence, and intuition to undertake unfamiliar and challenging tasks (Anguera et al., 2013; Baniqued et al., 2014; Gallen \& D’Esposito, 2019; Novakovic-Agopian et al., 2011; Temple et al., 2003). From these discussions, we see many recent developments are happening in the field of CST and there are possibilities for new opportunities in improving teaching and learning methods by integrating ancient wisdom with CST. Therefore we propose to test the role of the Brighter Minds method based CST on cognitive skills of healthy children and accordingly following null hypothesis is stated.

H0: There is no significant difference between pre and post-session of BM-based CST on cognitive skills such as memory retrieval, concentration, confidence, intuition, and blindfold reading of healthy children.

We could see there are five aspects of cognitive skills that are part of the null hypothesis, so the five Sub-Null Hypotheses are discussed in the following section. 
Supekar et al. (2021) in his study found that cognitive training to healthy children can lead to improvement in their problem solving skills through efficient memory retrieval. CST on functional and social aspects is not only effective for healthy children but it could also improve creativity, working speed, verbal and working memory, and concentration of the persons even with poor mental functioning Sampedro et al. (2021). In another study, an eight week short-term cognitive training for school children was found to bring long-term neuro-developmental changes, the results of this study demonstrated gain in memory-based strategies among participants (Rosenberg et al., 2018). As a part of CST when 20-min brain training sessions per week for four months were given to school children, an increase in confidence and concentration was noticed leading to gain in school-administered math and reading achievement tests (Wexler et al., 2016). From these reviews, we see that CST focuses on bringing positive changes in memory, concentration, and confidence of participants, at the same time it is also noticed that cognitive training could be of different durations and follow different methods which in turn influence the learning outcomes. However, to the best of our knowledge, none of the studies evaluated the effect of CST based on BM on memory, confidence, and concentration of healthy young children in a single study. Thus, we propose to test the effect of BM based CST on cognitive skills of healthy young children and the following sub hypotheses are stated accordingly:

$\mathrm{HO}_{1}$ : There is no significant difference in pre and post-session of CST concerning student's memory.

$\mathrm{HO}_{2}$ : There is no significant difference in pre and post-session of CST concerning student's confidence.

$\mathrm{HO}_{3}$ : There is no significant difference in pre and post-session of CST concerning student's concentration.

Two more cognitive traits that we propose are influenced by CST are intuition and blindfold reading abilities. Visuospatial representation and understanding of body spaces are known to influence the intuition abilities of a person. An in-depth discussion on visuospatial representation and various spaces of the body is made by Teversky (2005) where it is elaborated that visuospatial representation is especially important in developing an intuition for assigning meaning to objects around us and recalling when needed. He also explained that student's ability to understand and reflect on the objects around them is affected by an understanding of their body spaces. Teversky (2005) remains inconclusive that whether intuition abilities could be enhanced through cognitive skill training and we found there isn't much literature on this which motivated us to test the relationship between CST and Intuition and thus following hypothesis is stated.

$\mathrm{HO}_{4}$ : There is no significant difference in pre and post-session of CST concerning student's intuition ability.

A person's ability to learn and represent something that is beyond one's physical reach and not visible is embedded in a concept of 'out-of-body experiences' (OBE) (Paersall, 1972; Revonsuo, 2010). This is similar to reading writing, painting blindfold (Metzinger, 2008; Pfeiffer, 2015). Blanke et al. (2004) claimed that the brain can be trained for OBE. Yet there are other researchers who are not convinced that through OBE one could retrieve inaccessible information from the world such as reading a number on a piece of paper kept out of sight (Blackmore, 1986; Revonsuo, 
2010). Since the capability of doing blindfold activities can make a person much more efficient, it is worth evaluating whether BM based CST could enhance blindfold activities, therefore to test this relationship following hypothesis is stated:

$\mathrm{HO}_{5}$ : There is no significant difference in pre and post-session of CST concerning student's blindfold reading.

Evidences in the literature shows that through Upanishadic wisdom it is possible to achieve superior cognitive learning capabilities (Hiriyanna, 2005; Ramabrahmam, 2005). There are also evidences in the literature that posit the possibility of cognitive learning beyond normal capabilities through selective training interventions (Blanke et al., 2004; Pfeiffer, 2015). However, this idea is not universally accepted as some researchers raise doubts about achieving extraordinary learning outcomes through cognitive training particularly gaining capabilities such as beyond sight information retrieval/reading and improving the understanding of body spaces (Blackmore, 1986; Teversky, 2005). Since cognitive skill training being an important aspect of the contemporary teaching and learning environment, we felt there is a pressing need to bring clarity on this issue.

Another aspect that motivated us to conduct this study is, from review of the literature we found that the effectiveness of cognitive training depends upon the method and technique adopted; and many different methods have been practiced by a clinical psychologist under the umbrella term Cognitive Behavioural Therapy (CBT) since the 1960s (Anguera et al., 2013; Baniqued et al., 2014; Gallen \& D'Esposito, 2019; Novakovic-Agopian et al., 2011; Temple et al., 2003). CBT in spite of being an established cognitive and behavioural enhancement field of study, yet its application mainly focuses on the treatment of children with deficiencies (Benjamin et al., 2011), and its application for cognitive skill training of healthy children is not much practiced hence through this study we attempt to extend the scope of cognitive skill training to young healthy children.

In a previous study on CST based on the Brighter Minds method, in comparison to other techniques of CST, authors observed that for cognitive training of healthy children this method is effective and has high levels of satisfaction and acceptance among parents (Bongarala \& Jayanna, 2019). Seeing the encouraging results of CST based on the BM method, in this study we have evaluated the hypotheses for effect of CST through this method.

\section{Methodology}

\section{Study design}

In this study; subjects were evaluated pre and post CST interventions based on BM methods for the changes in their cognitive skills. The study adopted a mixed-method design having both quantitative and qualitative assessments. The quantitative study focussed on the assessment of changes in cognitive skills such as memory, intuition, confidence, thinking to feeling approach (intuition), blindfold activities before and after the training was conducted. Qualitative assessments through focused group discussions were also carried out after the training to document the observations and experiences of the parents and teachers on changes in cognitive skills of subjects. 


\section{Sample of study}

The training facility was suited for a batch of 30 students, so a sample of 30 volunteers was chosen to conduct the study. In order to gain the interest of students to participate in the study, we made presentations to the students of two large schools in the capital of Uttar Pradesh, India. All those students who showed interest to participate in the study were invited to attend a final counselling session along with their parents where terms and conditions for participating in study were explained. After counselling session 53 volunteers were finally willing to continue, among them 30 were randomly picked as sample of the study. These final 30 volunteers after filling up the registration form underwent CST based on BM methods in Lucknow district of Uttar Pradesh, India between May 2019 and November 2019. Baseline data were collected from these 30 volunteers, 02 students did not complete the sessions hence we had 28 volunteers for completing the study. The same children were met after the completion of the training for the endline data collection. The volunteer students were boys and girls both of age range 5 to 15 years. Only healthy students with normal cognitive functioning have been included in the study.

\section{Study team}

The study was conducted by a team comprising of experts from the background of management, research and evaluation, psychology, psychiatry, community health, and the Brighter Minds intervention team. These members were needed to support the study, for example, all the group formation responsibilities and coordination of background activities were conducted by a team member with managerial skills. The researcher helped in data collection, the psychologist helped in framing the measurement statements as well as monitored the volunteers during the sessions. Since volunteers were subjected to training that involved bringing changes in their minds and following a specific pattern of living including food habits over a period of time, as a precaution, we involved psychiatrist and community health specialist to take support if needed. Brighter Minds intervention team conducted the CST sessions. The experts were regular contributors of Brighter Minds programs and they volunteered to the support the study including screening the participants and conducting the focused group study.

\section{Tools}

\section{Quantitative tools}

In this study, the descriptive statistics for mean calculation, paired $t$ test for the comparison between pre and post-study of CST session, pie and bar chart for simple pictorial presentation of data is used.

\section{Measurement variables}

In this investigation, five measurement variables were selected for the study each relating to memory, confidence, concentration, intuition ability, and blindfold reading. Data for all the measurement variables were collected pre and post brighter minds sessions. Four measurement variables were measured on a 10 point Likert scale describing (near to 1 is poor and 10 is excellent). A blindfold reading variable was measured on a 10 point Likert scale describing ( 1 cannot read and near to 10 can easily read). Single item constructs 
were used for measuring the variables. The items for measuring variables were adopted after consultation with team of experts supporting the study. Apart from these behavioural variables, two variables, gender, and age were also measured on nominal scale.

\section{Qualitative tools}

The role of parents in the assessment of cognitive learning has been found important in managing the cognitive learning challenges of children (Syriopoulou-Delli, et al., 2019). Therefore focus group discussions were conducted among parents and teachers to capture their observations and experiences regarding changes in cognitive traits of participating students and cross-validate the findings of quantitative analyses. The focused group discussion was conducted after the second round of data collection from volunteers was completed.

\section{Data collection}

Parents and teachers were briefed about the purpose of the study; the students were also explained about the process and tools of the study and their formal consent was obtained. Pre-intervention and post-intervention tests were carried out ensuring appropriate auditory and visual privacy. The questionnaire was administered directly by the authors along with team members. Pre-intervention assessments were carried out at the start of the CST. The students underwent thirty hours of training for eight weeks. Postintervention assessments were carried out with the same students.

\section{Data analysis}

Data were analyzed using the Statistical Package for Social Science (SPSS 23.0). Participants who completed both pre-test and post-test assessments were included in the analysis. A paired sample $t$ test was carried out on pairs of scores for each outcome to determine the statistical significance of gains from pre to post interventions. The set level of confidence for the acceptance or rejection of the study hypothesis was $\alpha=0.05$ which means if the significance value ( $p$-value) is less than 0.05 then we reject the Null Hypothesis and if the significance value is more than 0.05 then the Null Hypothesis is accepted.

\section{Results and findings}

Demographic profile

From Figs. 2 and 3 it is clear that the minimum age was 7 years and the maximum age was 15 years in this CST session. It is also clear that every age group students between 7 to 15 years have participated in this study and it is also very clear that $71.43 \%$ (20) students were a boy and $28.57 \%$ (8) students were a girl, hence most of the students in the study are boys.

\section{Paired $t$ test}

Memory

A 10 point Likert scale for the measurement for memory, confidence, concentration, and intuition ability was used in such a way that near to 1 means very poor and near to 10 is excellent. From Table 1 and Fig. 4, the mean score of memory was 


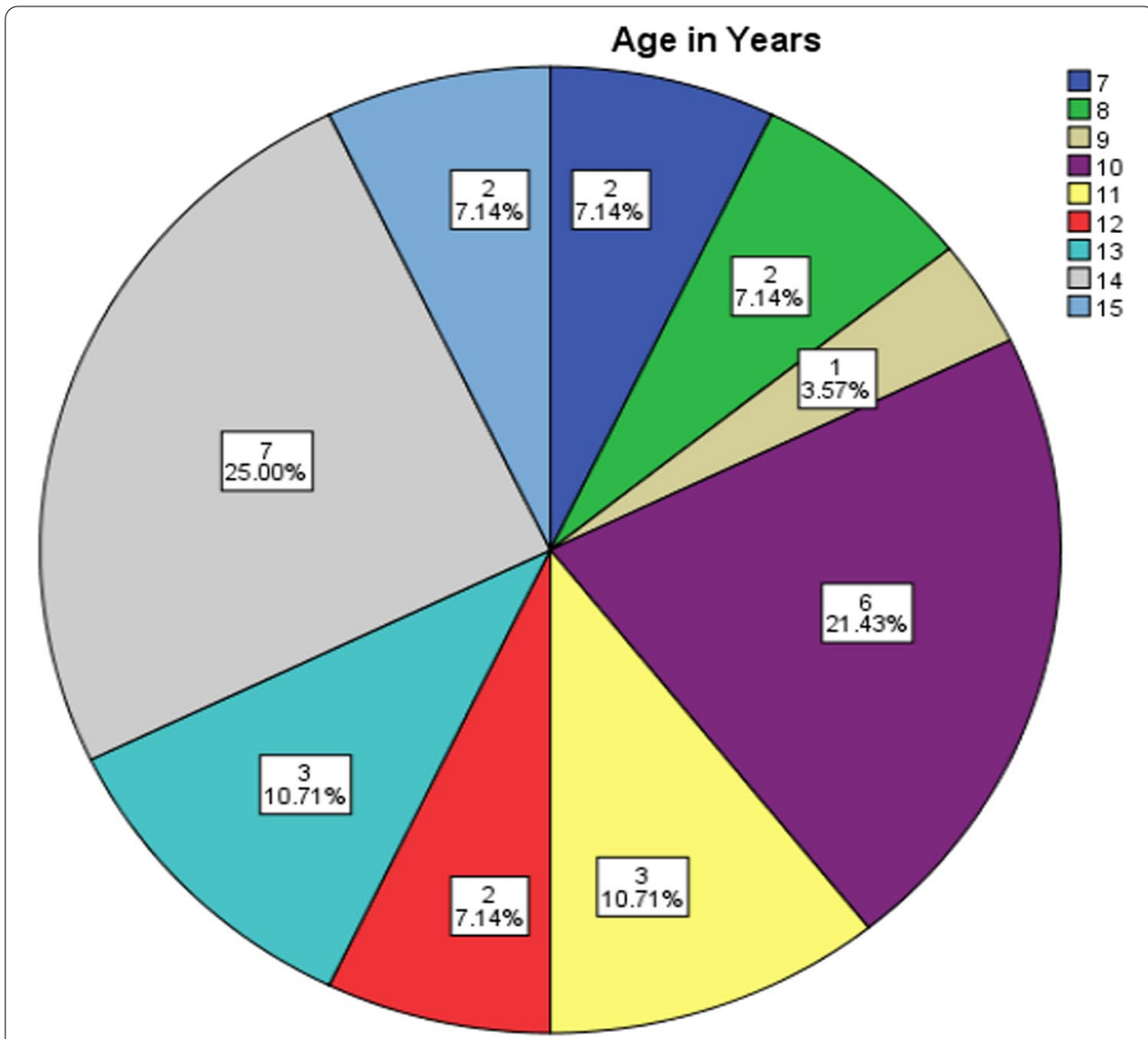

Fig. 2 Age. Source: SPSS 23.0 output

7 in pre-session and 8.29 in post CST session, therefore it can be concluded that there was an improvement of student's memory after completion of brighter minds sessions.

Since the null hypothesis was $\mathrm{HO}_{1}$ : There is no significant difference in pre and post-session of Brighter Minds concerning student's memory. From Table 2, the sig. value ( $\mathrm{p}$-value $=0.000$ ) is less than 0.05 , hence it was safe to reject the null hypothesis, therefore it can be concluded that there is a significant difference in pre and post-session of Brighter Minds concerning students' memory.

\section{Confidence}

From Table 3 and Fig. 5, the mean score of confidence was 6.79 in pre-session and 8.14 in post-CST session, therefore it can be concluded that there was an improvement in student's confidence.

Since the null hypothesis was $\mathrm{HO}_{2}$ : There is no significant difference in pre and post-session CST concerning student's confidence. From Table 4, the sig. value ( $p$-value $=0.000)$ is less than 0.05 , hence it was safe to reject the null hypothesis, therefore it can be concluded that there is a significant difference in pre and postsession of CST concerning students' confidence. 


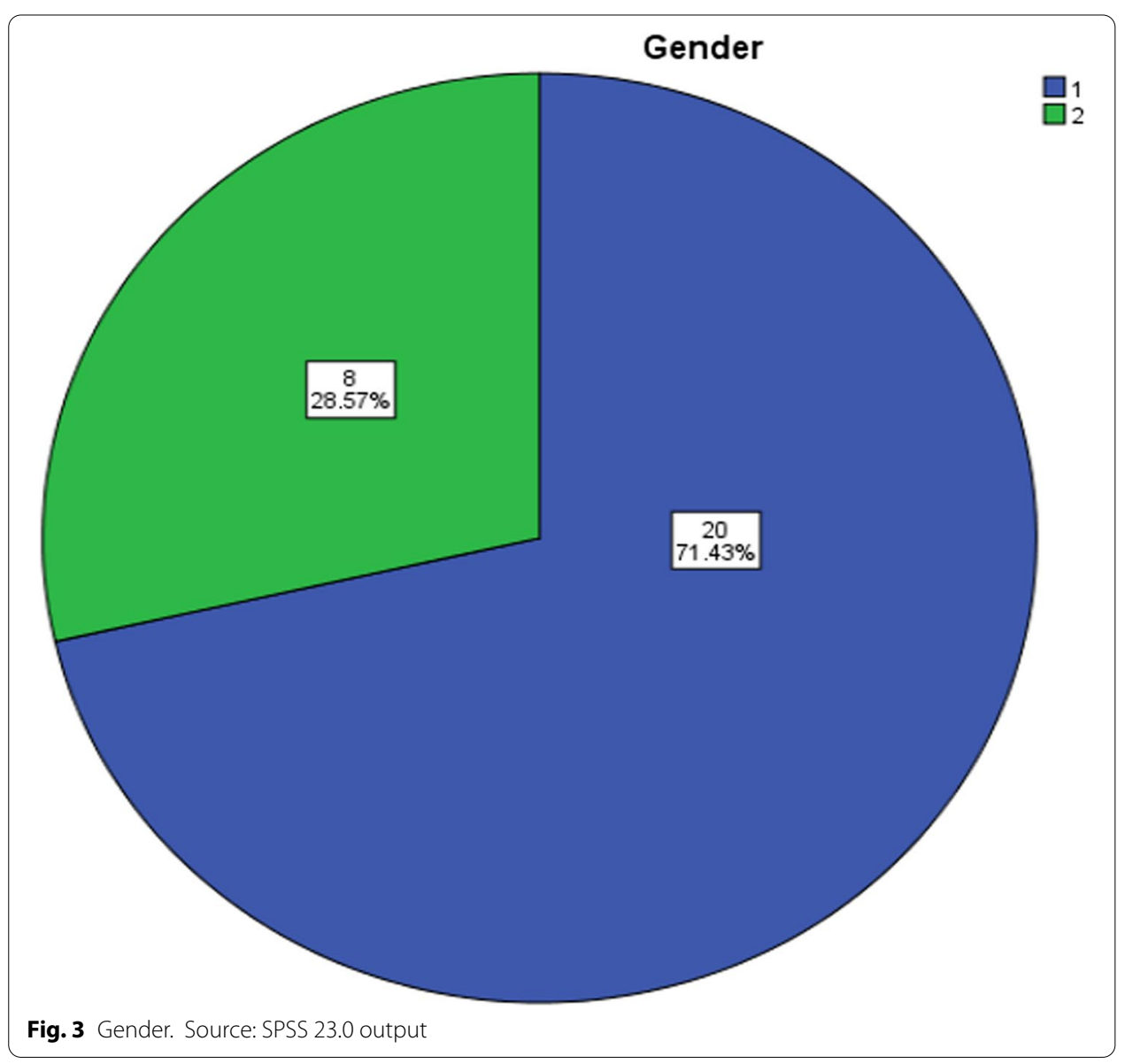

Table 1 Paired samples statistics: memory. Source: SPSS 23.0 output

\begin{tabular}{lllll}
\hline & Mean & N & SD & SE mean \\
\hline Pair 1 & & & & \\
Memory pre & 7.00 & 28 & 1.388 & .262 \\
Memory post & 8.29 & 28 & 1.512 & .286 \\
\hline
\end{tabular}

\section{Concentration}

From Table 5 and Fig. 6, the mean score of concentration was 6.43 in pre-session and 7.79 in post-CST session, therefore it can be concluded that there was an improvement in student's concentration.

Since the null hypothesis was $\mathrm{HO}_{3}$ : There is no significant difference in pre and post-session CST concerning student's concentration. From Table 6, the sig. value (p-value $=0.000$ ) is less than 0.05 , hence it was safe to reject the null hypothesis, therefore it can be concluded that there is a significant difference in pre and postsession of CST concerning students' concentration. 


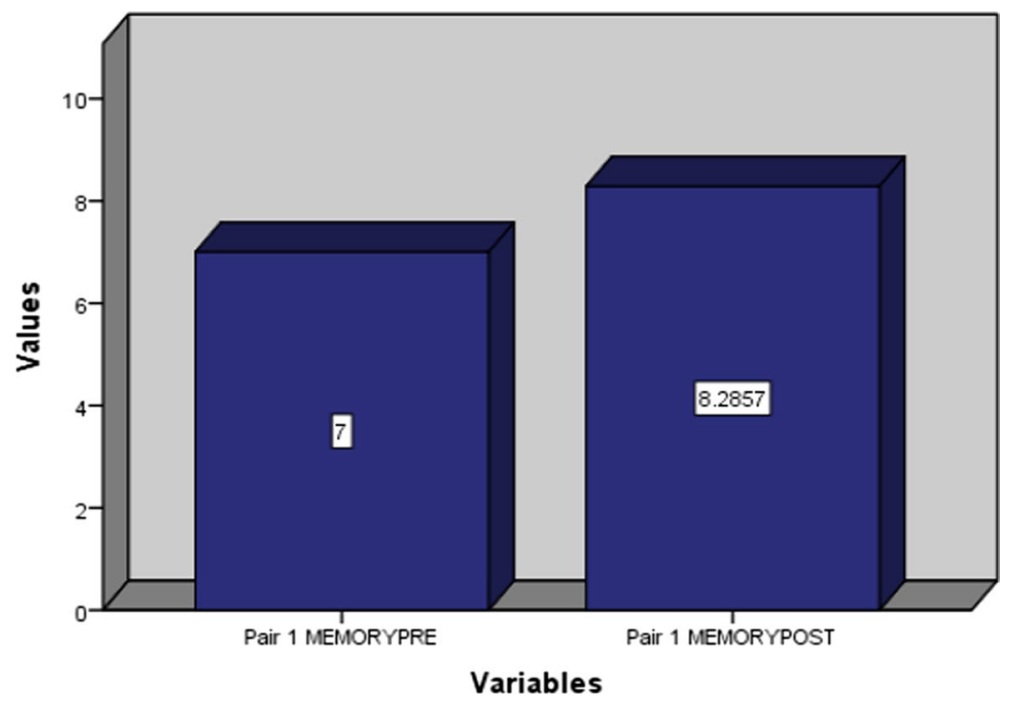

Fig. 4 Paired samples statistics: memory. Source: SPSS 23.0 output

Table 2 Paired samples test: memory. Source: SPSS 23.0 output

\begin{tabular}{|c|c|c|c|c|c|c|c|c|c|}
\hline & \multicolumn{5}{|c|}{ Paired differences } & \multirow[t]{3}{*}{$\mathbf{t}$} & \multirow[t]{3}{*}{ df } & \multirow[t]{3}{*}{ Sig. (2-tailed) } & \multirow[t]{3}{*}{ Results } \\
\hline & \multirow[t]{2}{*}{ Mean } & \multirow[t]{2}{*}{ SD } & \multirow[t]{2}{*}{ SE Mean } & \multicolumn{2}{|c|}{$\begin{array}{l}95 \% \text { Confidence } \\
\text { interval of the } \\
\text { difference }\end{array}$} & & & & \\
\hline & & & & Lower & Upper & & & & \\
\hline \multicolumn{10}{|l|}{ Pair 1} \\
\hline $\begin{array}{l}\text { Memory pre } \\
\text { Memory } \\
\text { post }\end{array}$ & -1.29 & 1.182 & .223 & -1.744 & -.827 & -5.756 & 27 & .000 & Significant \\
\hline
\end{tabular}

Table 3 Paired samples statistics: confidence. Source: SPSS 23.0 output

\begin{tabular}{lllll}
\hline & Mean & N & SD & SE mean \\
\hline Pair 1 & & & & \\
Confidence pre & 6.79 & 28 & 1.813 & .343 \\
Confidence post & 8.14 & 28 & 1.758 & .332 \\
\hline
\end{tabular}

\section{Intuition ability}

From Table 7 and Fig. 7, the mean score of intuition ability was 6.29 in pre-session and 6.86 in post-CST session, therefore it can be concluded that there was an improvement of student's intuition ability.

Since the null hypothesis was $\mathrm{HO}_{4}$ : There is no significant difference in pre and post-session CST concerning student's intuition ability. From Table 8, the sig. value (p-value $=0.030$ ) is less than 0.05 , hence it was safe to reject the null hypothesis, therefore it can be concluded that there is a significant difference in pre and postsession of CST concerning students' intuition ability. 


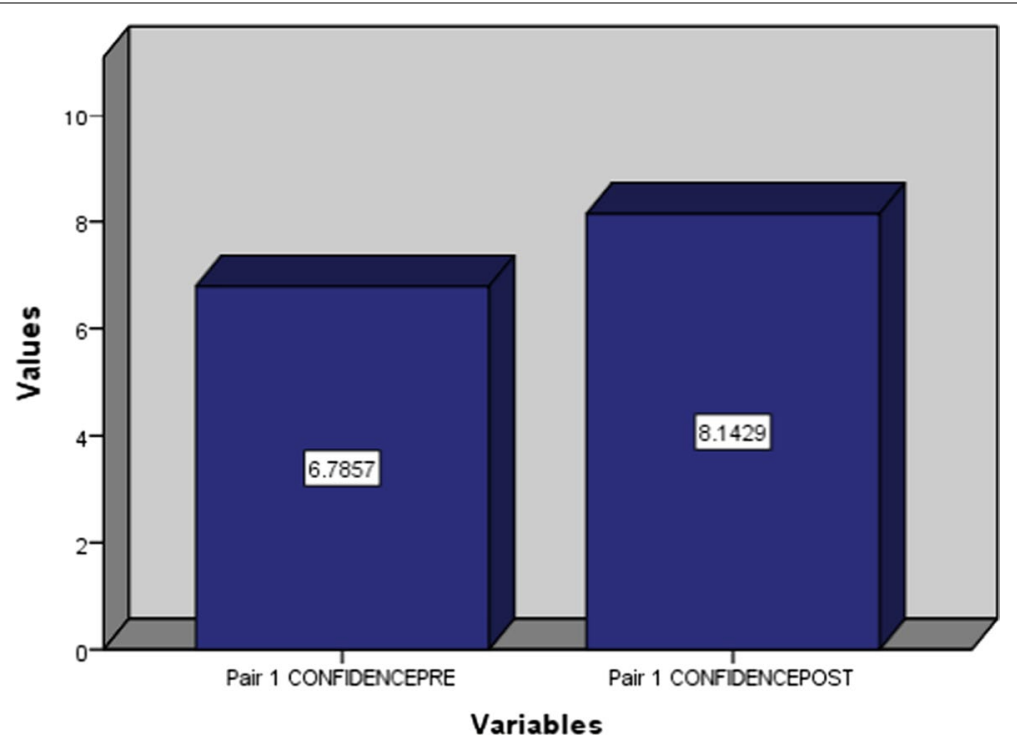

Fig. 5 Paired samples statistics: confidence. Source: SPSS 23.0 output

Table 4 Paired samples test: confidence. Source: SPSS 23.0 output

\begin{tabular}{|c|c|c|c|c|c|c|c|c|c|}
\hline & $\begin{array}{l}\text { Paired } \\
\text { differences }\end{array}$ & & & & & $t$ & df & $\begin{array}{l}\text { Sig. } \\
\text { (2-tailed) }\end{array}$ & Results \\
\hline & Mean & SD & SE mean & $\begin{array}{l}95 \% \\
\text { Confidence } \\
\text { Interval } \\
\text { of the } \\
\text { Difference }\end{array}$ & & & & & \\
\hline & & & & Lower & Upper & & & & \\
\hline Pair 1 & & & & & & & & & \\
\hline $\begin{array}{l}\text { Confi- } \\
\text { dence pre } \\
\text { Confi- } \\
\text { dence } \\
\text { post }\end{array}$ & -1.36 & 1.367 & .258 & -1.887 & -.827 & -5.255 & 27 & .000 & Significant \\
\hline
\end{tabular}

Table 5 Paired samples statistics: concentration. Source: SPSS 23.0 output

\begin{tabular}{lllll}
\hline & Mean & N & SD & SE mean \\
\hline Pair 1 & & & & \\
Concentration pre & 6.43 & 28 & 1.709 & .323 \\
Concentration post & 7.79 & 28 & 1.729 & .327 \\
\hline
\end{tabular}

\section{Blindfold reading/colour identification}

A 10 point Likert scale for the measurement for Blindfold reading/colour identification was used in such a way that 1 means cannot read or identify colours and near to 10 is easily read and identify colours with a blindfold. From Table 9 and Fig. 8, the mean score of blindfold reading/colour identification was 1 in pre-session and 6.89 in 




Fig. 6 Paired samples statistics: concentration Source: SPSS 23.0 output

Table 6 Paired samples test: concentration. Source: SPSS 23.0 output

\begin{tabular}{|c|c|c|c|c|c|c|c|c|c|}
\hline & \multicolumn{5}{|c|}{ Paired differences } & \multirow[t]{3}{*}{$\mathbf{t}$} & \multirow[t]{3}{*}{ df } & \multirow[t]{3}{*}{ Sig. (2-tailed) } & \multirow[t]{3}{*}{ Results } \\
\hline & \multirow[t]{2}{*}{ Mean } & \multirow[t]{2}{*}{ SD } & \multirow[t]{2}{*}{ SE mean } & \multicolumn{2}{|c|}{$\begin{array}{l}95 \% \text { Confidence } \\
\text { interval of the } \\
\text { difference }\end{array}$} & & & & \\
\hline & & & & Lower & Upper & & & & \\
\hline \multicolumn{10}{|l|}{ Pair 1} \\
\hline $\begin{array}{l}\text { Concen- } \\
\text { tration } \\
\text { pre } \\
\text { Concen- } \\
\text { tration } \\
\text { post }\end{array}$ & -1.35 & 1.254 & .237 & -1.843 & -.871 & -5.729 & 27 & .000 & Significant \\
\hline
\end{tabular}

Table 7 Paired samples statistics: intuition ability. Source: SPSS 23.0 output

\begin{tabular}{lllll}
\hline & Mean & N & SD & SE mean \\
\hline Pair 1 & & & & \\
Intuition ability pre & 6.29 & 28 & 1.782 & .337 \\
Intuition ability post & 6.86 & 28 & 2.305 & .436 \\
\hline
\end{tabular}

post-CST session, therefore it can be concluded that students acquired the reading/ colour identification skill after the post-session of CST.

Since the null hypothesis was $\mathrm{HO}_{5}$ : There is no significant difference in pre and postsession CST concerning student's blindfold reading. From Table 10, the sig. value ( $\mathrm{p}$-value $=0.000)$ is less than 0.05 , hence it was safe to reject the null hypothesis, therefore it can be concluded that there is a significant difference in pre and postsession of CST concerning students' blindfold reading/colour identification. 


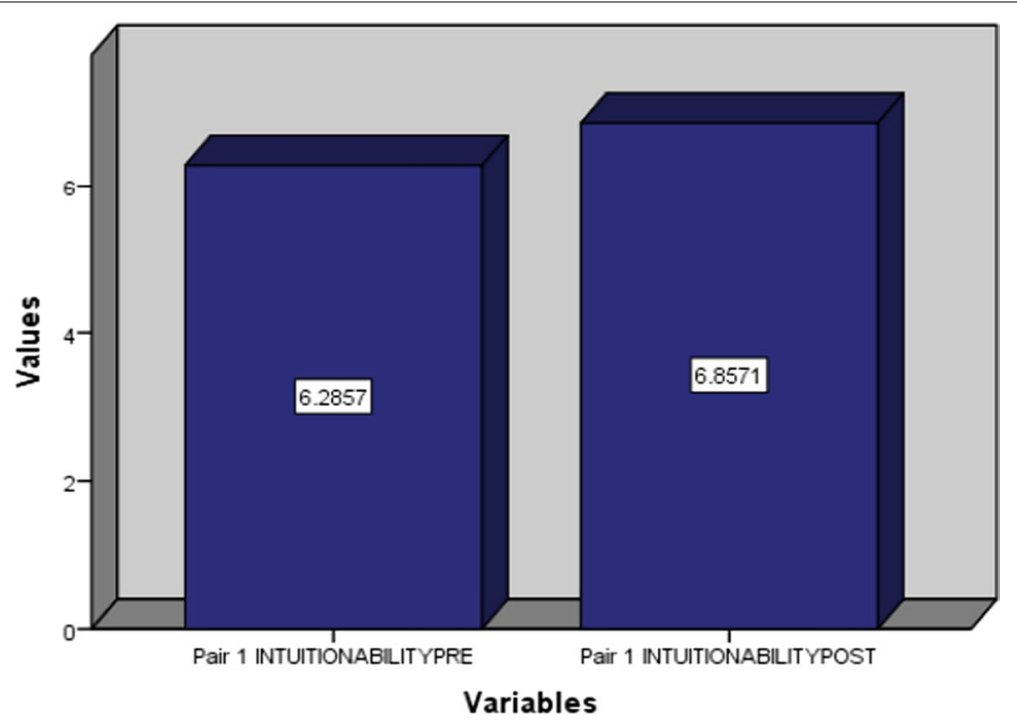

Fig. 7 Paired samples statistics: intuition ability. Source: SPSS 23.0 output

Table 8 Paired samples test: intuition ability. Source: SPSS 23.0 output

\begin{tabular}{|c|c|c|c|c|c|c|c|c|c|}
\hline & $\begin{array}{l}\text { Paired } \\
\text { differences }\end{array}$ & & & & & $\mathrm{t}$ & df & $\begin{array}{l}\text { Sig. } \\
\text { (2-tailed) }\end{array}$ & Results \\
\hline & \multirow[t]{2}{*}{ Mean } & \multirow[t]{2}{*}{ SD } & \multirow[t]{2}{*}{ SE mean } & \multicolumn{2}{|l|}{$\begin{array}{l}95 \% \\
\text { Confidence } \\
\text { interval } \\
\text { of the } \\
\text { difference }\end{array}$} & & & & \\
\hline & & & & Lower & Upper & & & & \\
\hline \multicolumn{10}{|l|}{ Pair 1} \\
\hline $\begin{array}{l}\text { Intui- } \\
\text { tion } \\
\text { ability } \\
\text { pre } \\
\text { Intui- } \\
\text { tion } \\
\text { ability } \\
\text { post }\end{array}$ & -.571 & 1.317 & .249 & -1.082 & -.061 & -2.29 & 27 & .030 & Significant \\
\hline
\end{tabular}

Table 9 Paired samples statistics: blindfold reading/colour identification. Source: SPSS 23.0 output

\begin{tabular}{lcccc}
\hline & Mean & N & SD & SE mean \\
\hline Pair 1 & & & & \\
Blindfold reading pre & 1.00 & 28 & .000 & .000 \\
Blindfold reading post & 6.89 & 28 & 2.149 & .406 \\
\hline
\end{tabular}

\section{Conclusion}

Since the Mean scores of post-CST are higher than pre-CST and the difference is statistically significant for all the five variables, the result of our research confirms the effectiveness of two months of CST sessions in improving the cognitive skills of 


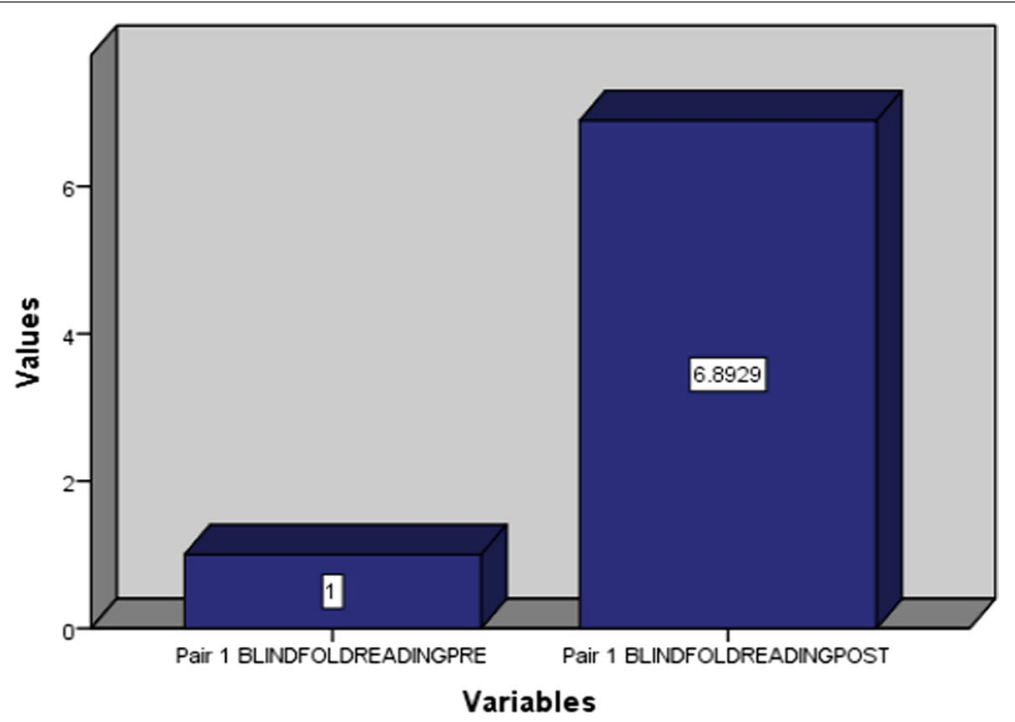

Fig. 8 Paired samples statistics: blindfold reading/colour identification. Source: SPSS 23.0 output

Table 10 Paired samples test: blindfold reading/colour identification. Source: SPSS 23.0 output

\begin{tabular}{|c|c|c|c|c|c|c|c|c|c|}
\hline & \multicolumn{5}{|c|}{ Paired differences } & \multirow[t]{3}{*}{$t$} & \multirow[t]{3}{*}{ df } & \multirow[t]{3}{*}{ Sig. (2-tailed) } & \multirow[t]{3}{*}{ Results } \\
\hline & \multirow[t]{2}{*}{ Mean } & \multirow[t]{2}{*}{ SD } & \multirow[t]{2}{*}{ SE mean } & \multicolumn{2}{|c|}{$\begin{array}{l}\text { 95\% Confidence } \\
\text { interval of the } \\
\text { difference }\end{array}$} & & & & \\
\hline & & & & Lower & Upper & & & & \\
\hline \multicolumn{10}{|l|}{ Pair 1} \\
\hline $\begin{array}{l}\text { Blindfold } \\
\text { reading } \\
\text { pre } \\
\text { Blindfold } \\
\text { reading } \\
\text { post }\end{array}$ & -5.89 & 2.149 & .406 & -6.726 & -5.06 & -14.51 & 27 & .000 & Significant \\
\hline
\end{tabular}

volunteers children aged between 7 to 15 years. Particularly we noticed a significant improvement in student's memory, confidence, concentration, intuition ability, and very important reading and colour identification with blindfolds. Findings of focused group discussions also confirm that the memory of the children has improved, confidence and concentration level was also increased. Sense of thinking to feeling is enhanced through the intuition ability, and most importantly, after completion of $30 \mathrm{~h}$ CST program, every student can read books, newspapers, etc. with a blindfold. It was also expressed by the parents and teachers that the students with blindfolds could draw painting, do distance sensing, obstacle walking, sorting and segregating as well as solve the puzzles including the Rubik's cube which is somewhat close to the findings of Bostelmann et al. (2020) that children of age 5-9 years could build a cognitive map in absence of visual information. In nutshell, there were extraordinary improvements in the cognitive capabilities of participating children. Therefore we conclude that through BM-based CST there is a possibility to enhance the cognitive capabilities 
of young children and thus, wider adoption of the CST programs could be helpful to deal with information overload and the complexity of the learning environment.

\section{Limitations and implications for future studies}

Among the limitations of this study one was, the students were selected between the age group of 5 to 15 years and hence we suggest avoiding generalization of findings to other population groups. The other limitation was the period of data collection; other studies could include multiple batches of CST over a larger period of time. The sample of this study was 28 and since a small sample could be the source of response biases, we suggest future research could opt for the a larger sample, adopt a more comprehensive scale, apply other methods of CST, and do conclusive research by recording the weekly changes in the student's behaviour during the CST Program. We believe that this small exploratory study would serve as a foundation for future larger scale studies to improve our understanding of developing cognitive skills through CST.

\section{Discussions and implications}

Ancient Indian wisdom on transcendental learning provides a promising foundation to reasonably believe that through practicing methods based on Upanishadic wisdom students could attain a higher state of consciousness and exhibit superior meta-cognitive learning capabilities. In today's teaching-learning environment where both the teacher and learner are constantly facing irrepressible pressure to exhibit superior learning outcomes, the adoption of Vedic systems becomes even more pertinent. BM-based CST Program provides a means to blend the Upanishadic wisdom with new-age technological methods that could unusually enhance cognitive learning capabilities. Our findings are in conformity with the arguments of Jijina et al. (2020) that India must look at its ancient scriptures that profoundly analysed the states of consciousness and mind as well as satiated the longings of knowledge seekers through successfully guiding 'Svadhayay' or self-learning for generations. The capability of participating children to read and write blindfold presents evidence for the modern-day application of the 'Panch Kosha' model of Taittiriya Upanishad which postulates through training one cold overcome the layer surrounding consciousness and achieve the fullness of the self and world (Hiriyanna, 2005; Swami Gambhirananda, 1958 cited in Raina, 2016). The findings up to some extent demystify the debate around possibilities of achieving extraordinary abilities through cognitive skill training and in this way the research adds fresh perspective to the literature on cognitive training grounded in the science of 'neuroeducation' and ancient knowledge of transcendental learning.

\section{Practical implications}

Governments around the world spend bravely to provide sound education to the citizens but in many cases, over years the gross outcome is dismal as students many times lack basic skills and fail to perform cognitive tasks even after completing primary education (PROBE, 1999, p. 27; Pratham, 2019, p. 48). The situation for developing countries around the world has been reported bleak long ago especially for primary education in rural communities (Bennett, 1970, p. 94) and not much difference has been achieved yet. Under such a situation CST ushers the possibility to improve the impact of the education 
system. If methods of CST are integrated into the curriculum of primary education the teaching-learning outcome could improve manifolds. Another advantage we found with the methods of BM is though it is scientific yet simple to execute, hence could easily be rolled out at a large scale.

\section{Social implications}

With the ever-increasing information load in the modern digitised society students and parents get emaciated while coping up. BM-based CST offered in 30 sessions imbibes modular format principles such as time to repetition, practice, and assessment following spiral curriculum, context-specific which is acknowledged to be effective for building cognitive and problem-solving skills (Cornford, 1997). Our findings show CST offers the opportunity to aspiring children to enhance their learning capabilities, address the learning challenges and stay competitive. Moreover, CST not only enhances cognitive skills such as memory, confidence, and concentration but also accentuates intuition and blindfold abilities that could remarkably enhance their contribution to society. Therefore in our opinion, if CST is adopted at a large scale in society, not only we would have bright mind children but mindful also.

At last, it could be concluded that the confluence of ancient wisdom with modern-day technology has immense potential to wake the conscientiousness of the children and so transform the society full of learned people with equanimity.

\section{Abbreviations}

BM: Brighter minds; CST: Cognitive skill training; SDG: Sustainable development goal; CBT: Cognitive behavioural therapy; OBE: Out-of-body experiences.

\section{Acknowledgements}

Not applicable.

\section{Authors' contributions}

This work was carried out in collaboration with all authors. All the authors contributed to the paper equally. The literature review, discussion, and conclusion are written by KM. The data analysis is performed by $\mathrm{W}$. The introduction of the study, data collection, methodology, and formatting of the paper is done by RKC. All authors read and approved the final manuscript.

\section{Funding}

No funding is received from any agency for this research work.

Availability of data and materials

The dataset used and/or analysed during the current study are available from the corresponding author on reasonable request.

Declaration

Competing interests

The authors declare that they have no competing interests.

Received: 25 September 2021 Accepted: 28 December 2021

Published online: 17 January 2022

\section{References}

Abrams, N. E., \& Primack, J. R. (2001). Cosmology and 21st-century culture. Science, 293, 1769-1770.

Anguera, J. A., et al. (2013). Video game training enhances cognitive control in older adults. Nature, 501, 97-101.

Baniqued, P. L., et al. (2014). Cognitive training with casual video games: Points to consider. Frontiers in Psychology, $4,1010$.

Baniqued, P. L., Gallen, C. L., et al. (2019). Brain network modularity predicts cognitive training-related gains in young adults. Neuropsychologia, 131, 205-215. https://doi.org/10.1016/j.neuropsychologia.2019.05.021 
Benjamin, C. L., Puleo, C. M., Settipani, C. A., Brodman, D. M., Edmunds, J. M., Cummings, C. M., \& Kendall, P. C. (2011). History of cognitive-behavioral therapy in youth. Child and Adolescent Psychiatric Clinics of North America, 20(2), 179-189. https://doi.org/10.1016/j.chc.2011.01.011

Bennett, N. (1970). Primary education in rural communities: An investment in ignorance? The Journal of Development Studies, 6(4), 92-103. https://doi.org/10.1080/00220387008421337

Bigliassi, M., Galano, B. M., Lima-Silva, A. E., \& Bertuzzi, R. (2020). Effects of mindfulness on psychological and psychophysiological responses during self-paced walking. Psychophysiology, 57, e13529. https://doi.org/10.1111/psyp.13529

Blackmore, S. J. (1986). The Adventures of a parapsychologist (p. 176). Prometheus Books.

Blanke, O., Landis, T., Spinelli, L., \& Seeck, M. (2004). Out-of-body experience and autoscopy of neurological origin. Brain, 127(2), 243-258. https://doi.org/10.1093/brain/awh040

Bongarala, M., \& Jayanna, K. (2019). Parents' perspective on effects and benefits of "brighter minds" cognitive training program: Results from an online survey in India. Creative Education, 10(01), 224-235. https://doi.org/10.4236/ce. 2019.101018

Bongarala, M., Kumar, S., Ross, R., Manjunatha, R., Nagaraja, N. S., \& Jayanna, K. (2019). Impact of a neuro-cognitive intervention on students' cognitive functions: Assessments in a government school setting in south India. Journal of Educational and Developmental Psychology, 9(2), 62. https://doi.org/10.5539/jedp.v9n2p62

Bostelmann, M., Lavenex, P., \& Banta Lavenex, P. (2020). Children five to nine years old can use path integration to build a cognitive map without vision. Cognitive Psychology, 121, 101307. https://doi.org/10.1016/j.cogpsych.2020.101307

Cornford, I. R. (1997). Ensuring effective learning from modular courses: A cognitive. Journal of Vocational Education \& Training, 49(2), 237-251. https://doi.org/10.1080/13636829700200014

Gallen, C. L., \& D'Esposito, M. (2019). Brain modularity: A biomarker of intervention-related plasticity. Trends in Cognitive Sciences, 23(4), 293-304. https://doi.org/10.1016/j.tics.2019.01.014

Ghosh, S. C. (2007). History of education in India. Rawat Publications.

Goswami, U. (2010). Neuroscience and education. British Journal of Educational Psychology, 74(1), 1-14. https://doi.org/10. 1348/000709904322848798

Hiriyanna, M. (2005). Outlines of Indian philosophy. Delhi, India: Motilal Banarsidass.

Jijina, P., Vasa, V., \& Biswas, U. N. (2020). Construct description of Samatva from the Bhagavad Gita: Implications for holistic well-being. Purshartha, 13(1), 1-20. https://doi.org/10.21844/16202013101

Katzir, T., \& Pare-Blagoev, J. (2006). Applying cognitive neuroscience research to education: The case of literacy. Educational Psychologist, $41(1), 53-74$.

Kleim, J. A., \& Jones, T. A. (2008). Principles of experience-dependent neural plasticity: Implications for rehabilitation after brain damage. Journal of Speech, Language, and Hearing Research, 51(1), 225-239.

Metzinger, T. (2008). Why are out-of-body experiences interesting for philosophers? The theoretical relevance of OBE research. Cortex, 45, 256-258. https://doi.org/10.1016/j.cortex.2008.09.004

Mikhailova, E. S., Kurgansky, A. V., Nushtaeva, R. A., et al. (2021). Intracortical directed connectivity for information retention in visual-spatial working memory. Doklady Biological Sciences, 500, 133-137. https://doi.org/10.1134/S0012 496621050070

Monk, A. H. (1968). What every Hindu ought to know. Bangalore, India: SahityaSindhu. https://swadhyaylibrary.org/Smt2k Col/Book/PDF/da1767eb-6253-40ce-abd9-9ff95ec0859f_20042020155532113.pdf (retrieved through login on 23/03/2021)

Novakovic-Agopian, T., et al. (2011). Rehabilitation of executive functioning with training in attention regulation applied to individually defined goals: A pilot study bridging theory, assessment, and treatment. Journal of Head Trauma Rehabilitation, 26, 325-338.

Pearsall, R. J. (2004). [1972]. Table-Rappers: The Victorians and the Occult (New ed.). The History Press Ltd. p. 197

Petzinger, G. M., Fisher, B. E., McEwen, S., Beeler, J. A., Walsh, J. P., \& Jakowec, M. W. (2013). Exercise-enhanced neuroplasticity targeting motor and cognitive circuitry in Parkinson's disease. The Lancet. Neurology, 12(7), 716-726. https://doi. org/10.1016/S1474-4422(13)70123-6

Pfeiffer, C. (2015). Multisensory spatial mechanisms of the bodily self and social cognition-A commentary on Vittorio Gallese and Valentina Cuccio. Open Mind. https://doi.org/10.15502/9783958570450.

Pratham. (2019). Annual status of education report 2019. New Delhi: ASER Centre, p. 48. http://img.asercentre.org/docs/ ASER\%202019/ASER2019\%20report\%20/aserreport2019earlyyearsfinal.pdf

Prieto-Jiménez, E., López-Catalán, L., López-Catalán, B., \& Domínguez-Fernández, G. (2021). Sustainable development goals and education: A bibliometric mapping analysis. Sustainability, 13(4), 2126. https://doi.org/10.3390/su130 42126

PROBE Team. (1999). Public report on basic education in India (p. 27). Oxford University Press.

Raina, M. K. (2016). The levels of human consciousness and creative functioning: Insights from the theory of Pancha kosha (five sheaths of consciousness). The Journal of Transpersonal Psychology, 48(2), 168-189.

Ramabrahmam, V. (1997). Meditation on the Self through Physics, Proceedings of the World Congress for the Synthesis of Science and Religion, Calcutta.

Ramabrahmam, V. (2004). A modern scientific awareness of Upanishadic Wisdom: Implications to Psychology and Artificial Intelligence, Proceedings of the World Congress on Vedic Sciences, Bangalore.

Ramabrahmam, V. (2005). Human cognitive process - an ancient Indian model. In the Proceedings of International Vedic Conference on Contribution of the Vedas to the world, 27-30 January 2005 at Department of Vedic Studies, Gurukul Kangri Viswavidyalaya, Haridwar, Uttaranchal, India.

Revonsuo, A. (2010). Consciousness: The science of subjectivity. Psychology Press.

Roeser, R. W. (2005). An introduction to Hindu India's contemplative psychological perspectives on motivation, self, and development. Religion and MotivationIn M. L. Maehr \& S. Karabenick (Eds.), Advances in motivation and achievement (Vol. 14, pp. 297-345). Elsevier.

Rosenberg, M. L., luculano, T., Bae, S. R., et al. (2018). Short-term cognitive training recapitulates hippocampal functional changes associated with one year of longitudinal skill development. Trends in Neuroscience and Education, 10, 19-29. https://doi.org/10.1016/j.tine.2017.12.001 
Sampedro, A., Peña, J., Sánchez, P., et al. (2021). Cognitive, creative, functional, and clinical symptom improvements in schizophrenia after an integrative cognitive remediation program: a randomized controlled trial. NPJ Schizophrenia, 7, 52. https://doi.org/10.1038/s41537-021-00181-0

Sharma, B. K. (2013b). Hindu educational ethos and practices as a possible source for local pedagogy. https://neltachoutari. wordpress.com/2013/07/01/hindu-educational-ethos-and-practices-as-a-possible-source-for-local-pedagogy/

Sharma, B. K. (2013). Hinduism and TESOL: Learning, teaching, and student-teacher relationships revisited. Language and Linguistics Compass, 7(2), 79-90.

Shaywitz, S. E., et al. (2003). Neural systems for compensation and persistence: Young adult outcome of childhood reading disability. Biological Psychiatry, 54(1), 25-33. https://doi.org/10.1016/S0006-3223(02)01836-X

Smith, H. (1992). Forgotten truth: The common vision of the world's religions. Harper.

Solis, S. L., Grotzer, T. A., \& Curtis, K. N. (2019). There must be a cat nearby: Kindergarteners reasoning about action at an attentional distance. Journal of Educational and Developmental Psychology, 9(2), 182-202. https://doi.org/10.5539/ jedp.v9n2p182

Sudhof, T. C., \& Malenka, R. C. (2008). Understanding synapses: Past, present, and future. Neuron, 60(3), 469-476.

Supekar, K., Chang, H., Mistry, P. K., et al. (2021). Neurocognitive modeling of latent memory processes reveals reorganization of hippocampal-cortical circuits underlying learning and efficient strategies. Commun Biol, 4, 405. https://doi. org/10.1038/s42003-021-01872

Syriopoulou-Delli, C. K., Polychronopoulou, S. A., Kolaitis, G. A., \& Antoniou, A.-S.G. (2019). Parents' perceptions on anxiety symptoms in children with autism spectrum disorder. Journal of Educational and Developmental Psychology, 9(2), 104 https://doi.org/10.5539/jedp.v9n2p104

Temple, E., Deutsch, G. K., Poldrack, R. A., Miller, S. L., Tallal, P., Merzenich, M. M., et al. (2003). Neural deficits in children with dyslexia ameliorated by behavioral remediation: Evidence from functional MRI. Proceedings of the National Academy of Sciences of the United States of America, 100, 2860. https://doi.org/10.1073/pnas.0030098100

Teversky. B. (2005). Functional significance of visuospatial reasoning in Handbook of higher-level visuospatial thinking. Cambridge, pp. N.a, https://www.researchgate.net/publication/232084383_Functional_significance_of_visuospati al_representations

Thaker, S. N. (2007). Hinduism and learning. In Non-perspectives of learning and knowing. S.B. Marriam and Associates eds., pp. 57-63, Krieger Publishing Company, Florida.

United Nations. (2021). Sustainable development. Department of Economic and Social affairs. Retrieved on March 23, 2021, from https://sdgs.un.org/goals/goal4

Wexler, B. E., Iseli, M., Leon, S., Zaggle, W., Rush, C., Goodman, A., Esatlmal, A., \& Bo, E. (2016). Cognitive priming and cognitive training: Immediate and far transfer to academic skills in children. Scientific Reports, 6, 32859. https://doi.org/10. 1038/srep32859

Wilber, K. (1993). The great chain of being. In Walsh, R., \& Vaughan, F. (Eds.), Paths beyond ego: The transpersonal vision (pp. 214-222). Los Angeles, CA: Tarcher.

\section{Publisher's Note}

Springer Nature remains neutral with regard to jurisdictional claims in published maps and institutional affiliations.

\section{Submit your manuscript to a SpringerOpen ${ }^{\circ}$ journal and benefit from:}

- Convenient online submission

- Rigorous peer review

- Open access: articles freely available online

High visibility within the field

- Retaining the copyright to your article

Submit your next manuscript at $\boldsymbol{\nabla}$ springeropen.com 